\title{
CLINICAL EVALUATION OF MONOLITHIC ZIRCONIA (5Y), LITHIUM DISILICATE AND MODIFIED PEEK CAD-CAM ENDOCROWN MATERIALS, 3-YEAR CLINICAL PROSPECTIVE STUDY
}

\author{
Raafat Abd El-Rhman Tammam Attia*
}

\begin{abstract}
Statement of problem. Endocrown is a novel style of onlay; nevertheless, dentists have not still fully understood the clinical implications of the selection of endocrown material.

Objective: To conclude clinically, if endocrowns are a dependable substitute to post-retained restorations for significantly broken endodontically treated teeth and which restorative materials are proficient customized for constructing endocrowns.

Material and methods. The clinical study is an open label, parallel groups conducted randomly at Assiut University Dental Hospital. The trial involved a total of 40 patients. After providing signed informed consent, patients are enrolled and classified into three groups according to random number of the type of material (lithium disilicate, monolithic zirconia and modified PEEK material). Therapy distribution will be equalized (1:1:1). Endocrowns will be bonded by adhesive dual-cured luting resin composite. Medical assessments will be accomplished at zero, 6-M,12M,18-M,24-M,30-M and at 36 months following handling according to modified US Public Health Service criteria with dual self-sufficient assessors. The criteria will be evaluated are the Marginal fit, Marginal discoloration, Anatomic contour, Surface texture, Color match). Entirely obtained data will be desperctively investigated and survival probabilities were calculated by indicated statistics by an independent statistician.
\end{abstract}

Results: Afterward, an examination period of 3 years, endurance ratios were $94.87 \%$. one restoration replaced due to clinically improper failure and another after debonding rebonding again. There is an increase of Charlie ratings at 36 months in marginal fit among cases Zirconia 6 (50\%) whereas Charlie ratings in marginal discoloration are observed at the same among cases modified PEEK 6 (50\%). Color match and anatomic form were excellent for ceramic materials but good in start for modified PEEK then progressed to Charlie rate at 36-month examination. Finally, the best material was lithium disilicate, translucent zirconia, and PEEK material respectively.

Conclusions: Bonding endocrown restorations displayed a promising clinical functioning ended an examination time of 3 years $(94.87 \%)$. Clinical relevance of translucent zirconia, lithium disilicate ceramic and modified PEEK materials are a proper restorative management choice for molar endocrown. But scheduled clinical longstanding documents should be scheduled.

* Professor and Consultant of Fixed Prosthodontics, Implantology and Cosmotic Dentistry, Faculty pf Dentistry, Assiut University, Egypt. 


\section{INTRODUCTION}

Based on the 2016 systematic review reduction, the accessible literature suggests that direct combined resin or inflow / only restoration works the same or better than conventional treatments. Nevertheless, attention be obliged to clarifying the outcomes of laboratory researches. Additional clinical investigations are required to approve that endocrown prosthetics are suitable option for endodontically treated teeth or not. ${ }^{(1)}$

Furthermore, In systemic review 2019, it has been concluded that Endocrown is a viable substitute to intraradicular post for molars and appear encouraging for premolars, A particular planning outline and a meticulous bond procedure must be followed, and the new nanocomposite resins and lithium disilicate seem to have advantages in the fabrication of endocrowns. ${ }^{(2)}$

An endocrown is a monobloc restoration that combines the crown and the core as a single unit. ${ }^{(3,4)}$ It covers all cusps with a circular shoulder margin and extends toward the pulpal floor. Endocrowns use the available surface provided by the axial sides of the pulp chamber as micro-mechanical retention, while the bonding agent resin cement acts as micromechanical retention.3,4 Endocrowns have been reported to be successful restorations for endodontically restored molars with widespread damage of tooth crown..$^{(5,6)}$

the results of clinical and in vitro studies agree that endocrowns are an excellent treatment solution. Excellent survival rates have been reported in the short, medium, and long term for molars restored in this way. Clinical performance is also satisfactory and comparable with that observed for molars restored by using crowns. In addition, endocrowns had fewer catastrophic failures than crowns (with or without post retained restoration), with $6 \%$ of root fractures for endocrowns and 29\% for crowns. Most failures found in endocrowns were due to loosening $(71 \%) .{ }^{(7)}$
Alongside through the fast advances in numerical dentistry, extra clinics, and lab. CAD/CAM materials have been established. In accordance with the modern categorization systems, totally dental ceramic prosthetic materials can be classified into 3 categories, according to the stage or phases present in their chemical structure: (1) glass matrix ceramics, (2) Polycrystalline ceramics, and (3) ResinMatrix ceramics. All the three types present reliable esthetic functioning, biomechanical performance, and biological compatibility ${ }^{(8,9)}$

Regarding to the material chosen for the production of endocrown have been strengthened, surface treated ceramics as it deliver mechanical force tolerable to bear masticatory force and acceptable adhesive force to dental compositions .$^{(10,11)}$ the excellent selection looks to be manually pressed or machinable techniques (CAD-CAM) ceramics strengthened with lithium disilicate. (12) Lithium disilicate shows elevated mechanical potency, outstanding bonding characteristics to dental tissues, ${ }^{(13)}$ and exceptional aesthetics, because the width and size of the ceramic substance used for endocrowns are superior than that of a usual ceramic crowns. ${ }^{(14)}$

$5 \mathrm{~mol} \%$ Y-Zirconia is a recent formula of zirconia, which has been advertised as "translucent" or "anterior" zirconia and meets ISO 6872: 2015 Type II, Class 4 flexural strength requirements. This formula of zirconia is in-between in force and esthetics to 3Y-PSZ and lithium disilicate. While this formula of zirconia is available from several companies, precise clinical proof is required to form advocated protocol for operating the of 5- mol \% $\mathrm{Y}-\mathrm{Z}$ as endocrowns. ${ }^{(15,16)}$

Based on an analysis handled in 2015, monolithic zirconia was described as the most suggested material for molar single restorations, and lithium disilicate as the most recommended material for anterior single restorations. These recommendation favorites can be certified to the positive mechanical 
characteristics of zirconia and the aesthetic criteria of lithium disilicate. The introduction of $5 \% \mathrm{Y}-\mathrm{ZP}$ promises the strength of zirconia with esthetics nearer to that of lithium disilicate, however, these applications must be estimated clinically. ${ }^{(17)}$

In addition, A modified PEEK blocks containing $20 \%$ ceramic fillers (Biohpp; Bredent Gmbh) has suitable biomechanical characteristics and exceptional biological compatibility. ${ }^{(18,19)}$ It can be consumed for the construction of restorations either by injection molding or CAD-CAM techniques. The benefits of utilizing this material are the removal of hypersensitive responses, worthy attrition challenge, suitable surface finishing, and little plaque attraction. ${ }^{(20)}$.

The main improvement of this modified PEEK material is a 4-GPa modulus of flexibility, creating it as flexible as bone and permitting it to work as a stress-breaker and decrease the strengths transmitted to the prostheses and the roots of teeth consequently. (21) This, in blend with respectable bonding characteristics to teeth tissues when bonded with resin adhesive luting agent, can render the usage of PEEK a feasible alternate for the rebuilding of endodontically restored tooth across the usage of
Endocrowns. ${ }^{(22-25)}$ Researches estimating the criteria of this material were inadequate. ${ }^{(26-29)}$ Current articles on this material have mostly been in laboratory.

The objectives of this prospective study was to assess the clinical functioning of endocrown restoration and to evaluate the oral properties of dissimilar restorative materials. For this study, the first null hypothesis is no statistically significant differences between the evaluated criteria across the follow-up periods, the second null hypothesis is no statistically significant differences between the evaluated criteria related to different restorative endocrown materials(5Y-Z, lithium disilicate and modified PEEK material) used with the age and gender correlated

\section{MATERIALS AND METHODS}

This is a prospective, double-blinded, open control study with three parallel equalized arms. Patients will be admitted to the Department of Prosthodontics, University Dental Hospital, Faculty of Dentistry, Assiut University, Egypt, scheduled between 2016 and 2019 H. Registration schedule, intervention and evaluation described as described in (table 1)

TABLE (1) Standard protocol items; recommendations for criteria and interval periods

\begin{tabular}{|c|c|c|c|c|c|c|c|c|c|}
\hline \multirow{2}{*}{\multicolumn{2}{|c|}{\begin{tabular}{|l|} 
Time \\
\end{tabular}}} & \multicolumn{8}{|c|}{ Study period } \\
\hline & & Pretreatment & Posttreatment & $6 \mathrm{M}$ & $12 \mathrm{M}$ & $18 \mathrm{M}$ & $24 \mathrm{M}$ & $30 \mathrm{M}$ & $36 \mathrm{M}$ \\
\hline \multicolumn{2}{|c|}{ Registration } & $x$ & & & & & & & \\
\hline \multicolumn{2}{|c|}{ Fitness partition } & $x$ & & & & & & & \\
\hline \multicolumn{2}{|c|}{ Informed consent } & $x$ & & & & & & & \\
\hline \multicolumn{2}{|c|}{ Baseline data collection } & $x$ & & & & & & & \\
\hline \multicolumn{2}{|c|}{ Randomized subject } & $x$ & & & & & & & \\
\hline \multicolumn{2}{|l|}{ Allocation } & $x$ & & & & & & & \\
\hline \multirow{3}{*}{$\begin{array}{l}\text { Type of } \\
\text { material }\end{array}$} & Lithium disilicate ceramic & $x$ & & & & & & & \\
\hline & Zirconia & $x$ & & & & & & & \\
\hline & PEEK & $x$ & & & & & & & \\
\hline \multirow{5}{*}{$\begin{array}{l}\text { Modified } \\
\text { USPHS } \\
\text { criteria }\end{array}$} & 1. Interproximal contact & $x$ & $x$ & $x$ & $x$ & $x$ & $x$ & $x$ & $\times$ \\
\hline & 2. Occlusal surface contact & & & & & & & & \\
\hline & 3. Secondary caries & $x$ & $x$ & $x$ & $x$ & $x$ & $x$ & $x$ & $x$ \\
\hline & 4. Tooth integrity & $x$ & $x$ & $x$ & $x$ & $x$ & $x$ & $x$ & $x$ \\
\hline & 5. Patient satisfaction & $x$ & $x$ & $x$ & $x$ & $x$ & $x$ & $x$ & $x$ \\
\hline
\end{tabular}




\section{Inclusion criteria}

1. The participant is fit and is $20-55$ ages old and has Endodontically treated first molar treated teeth indicated to endocrown restoration with lack of diagnosis of a periapical lesion, fistula, swelling of periodontal tissues, atypical tooth movement, history of sensitivity to pressure, and no root breakage, as clarified by $\mathrm{x}$-ray.

2. The participant contains 3 or 4 sides of the integral tooth material after the whole root canal treatment.

3. The participant maintains excellent oral cleanliness and normal occlusion with opposing natural teeth.

4. The participant permits signaled a notified consent form.

5. Participants wanting to return for follow-up inspections and evaluations and not sharing in any other clinical assessment.

6. Participants, are bodily and mentally up to stand usual restorative protocols.

7. The participant has obtained a Class A measurement along with the modified US Public Health Service (USPHS) criteria after insertion of the endocrown.

\section{Exclusion criteria}

1. Discernable damage of the periapical tissue or occurrence of large cysts or both

2. Patients with poor oral hygiene and Serious periodontitis

3. Oral cancer (s)

4. Undertaking radiation treatment

5. Pregnancy

6. Psychological disorder or systemic disorders

7. Incompetent of self-care

8. Unacceptable for the study as reasoned by the investigators
9. Participants suffer from parafunctional habits (e.g. bruxism)

Enrollment: Patients who meet the inclusion criteria are selected from the Dental Clinics of the Department of Fixed Prosthodontics, Assiut University (Internal Recruitment). Patients are examined until the target number is reached (sequential sampling). Sample size: 13 patients in each group can reject the null hypothesis that the case indicators are equal probability (power) of 0.8 . This number should be increased to 14 in a group to cover possible losses during subsequent actions.

Participants: Forty patients will be admitted according to specific enrollment criteria. Random sorting will be done using computer-generated tables. This number will be hidden using allocated vague and sealed envelopes. Upon completion of the selection criteria, the 40 eligible participants will be arbitrarily allocated into three categories in the allotted ratio of 1: 1: 1 according to endocrown material used (lithium disilicate (IPS. Emax), monolithic zirconia and PEEK material) described in table (2).

Three dentists will contribute to this trial and all of them will have undergone regulated endocrown restoration exercises before the start of the study. The number of cases allocated to each dentist is unknown and differs due to factors beyond the control of the study. These three dentists will not be involved in any other procedures related to this clinical trial or data collection.

\section{Preparation Groups.}

The trial will be conducted on outpatient at Fixed Prosthodontics Clinic, Faculty of Dentistry, Assiut University. Followers will meet in the presence of patients on the initial visit. The procedures appointments will be designed as follows.

First Visit: Clinic secretary invites participants for preoperative documents before the tooth preparation process, facial adhesion reminder session, 
TABLE (2) Type, manufacturer, composition, and mechanical properties of 3 tested materials

\begin{tabular}{|c|c|c|c|c|c|c|c|}
\hline Material & Code & manufacturer & Ceramic type & Composition & $\begin{array}{l}\text { Modulus of } \\
\text { elasticity } \\
\text { (GPa) }\end{array}$ & $\begin{array}{c}\text { Flexure } \\
\text { strength } \\
(\mathrm{MPa})\end{array}$ & $\begin{array}{c}\text { Vickers } \\
\text { hardness } \\
(\mathrm{MPa})\end{array}$ \\
\hline $\begin{array}{l}\text { IPS e.max } \\
\text { CAD }\end{array}$ & $\mathrm{E}$ & $\begin{array}{l}\text { Ivoclar Vivadent } \\
\text { AG, Switzerland }\end{array}$ & $\begin{array}{c}\text { Lithium } \\
\text { disilicate glass- } \\
\text { ceramic }\end{array}$ & Glass-ceramic & 95 & 400 & 6000 \\
\hline Zenostar T & $\mathrm{Z}$ & $\begin{array}{c}\text { Wieland Dental + } \\
\text { Technik GmbH } \\
\text { \& Co. } \\
\text { KG, Pforzheim, } \\
\text { Germany }\end{array}$ & $\begin{array}{c}\text { Monolithic } \\
\text { translucent } \\
\text { zirconia }\end{array}$ & $\begin{array}{c}\mathrm{ZrO} 2+\mathrm{HfO} 2+\mathrm{Y} 2 \mathrm{O} 3 \\
\left(\_99 \%\right) \\
\mathrm{Y}_{2} \mathrm{O}_{3}\left(>4.5-\_6.0 \%\right), \mathrm{HfO}_{2} \\
\left(\_5 \%\right) \\
\mathrm{Al} 2 \mathrm{O} 3+\text { other oxides }\left(\_1 \%\right)\end{array}$ & 210 & 900 & 7000 \\
\hline $\begin{array}{c}\text { Modified } \\
\text { PEEK material }\end{array}$ & B & $\begin{array}{l}\text { BioHPP; Bredent } \\
\text { GmbH, Germany) }\end{array}$ & Resin ceramic & $\begin{array}{l}20 \% \text { ceramic } \\
\text { Fillers in resin matrix }\end{array}$ & 4 & 350 & 2300 \\
\hline
\end{tabular}

intra \& extra-oral clinical examination, radiographic examination, pre-operative photography, performance cast analysis, and waxing up process. Each participant is asked to sign a written consent letter in the Arabic patient's native languageSecond Visit: To prepare the teeth for the three groups for which an endocrowns restoration is planned, follow these procedures : (1) All deteriorated or broken parts of the teeth are eliminated and an anatomical occlusal cutback of $2 \mathrm{~mm}$ is achieved. reached to shape a smoothed 90-degree shoulder rim. (2) The guttapercha is peeled to an extent of not more than $2 \mathrm{~mm}$ and sealed with composite resin. (3) The undercuts of the dental cavity are blocked with a nano-hybrid composite resin, which serves as the base material. A 2 to 5-degree divergence of the vertical walls is made with a conical flat end tapered diamond drill. (4) Finish the cavity with the same rotary instrument that was used during preparation at a low rotation speed. Round off all interior walls to enable impression recordings and restoration siting and removal as following guidelines advocated. ${ }^{(30)}$ then secondary impressions and temporization. fig.1

(2) Make maxillary and mandibular polyvinyl siloxane impressions ((Elite HD; Zhermack$\mathrm{GmbH})$, and the working cast was poured with
Type IV dental stone (Prima-rock; Whip Mix Corp), which are then digitized. The anatomical outline determined following the catalog of the lab CADCAM system (Ceramill Motion 2; Amann Girrbach $A G)$. Introduce the different material blocks into the milling machine and grind the restoration, then the maturation of materials completed in a special furnace according to the manufacturer's instructions.

Related to the endocrown core was made of PEEK using conventional wax lost technology, using a vacuum press device (2 presses; Bredent $\mathrm{GmbH}$ ) developed for this material. The core was evaluated intraorally, and the fit was checked.

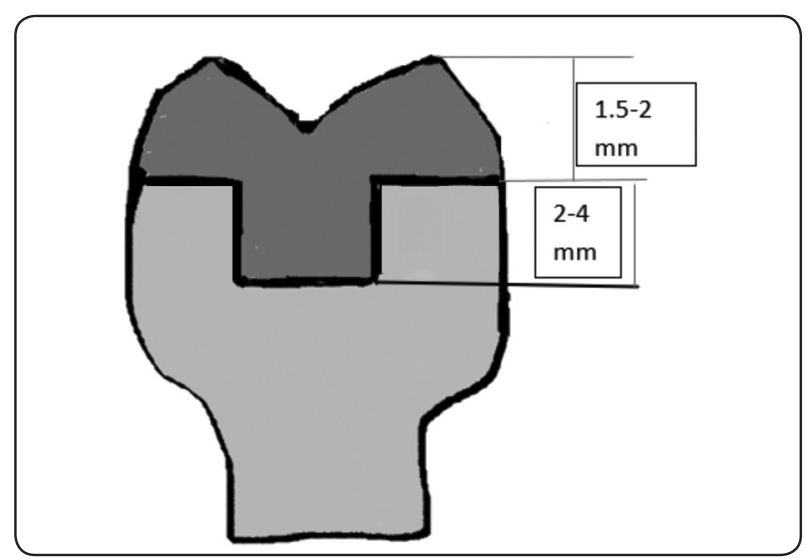

Fig. (1) Schematic representation of endocrown design 
The core of PEEK was coated with a composite polymer primer (Visio.link; Bredent $\mathrm{GmbH}$ ) and an indirect light-curing composite polymer facing material was applied in layers.

The restoration was accustomed intraorally and refined. The endocrown was sandblasted with 110 $\mathrm{mm}$ aluminum oxide and was finally bonded with dual-polymerizing resin cement (Variolink Esthetic DC; Ivoclar Vivadent AG) in the final visit.

Third Visit: Try in of the restoration according to the guidelines recommended.

Fourth Visit: patients were invited again for final delivery. All tested teeth receives a class A evaluation according to the modified USPHS criteria of all criteria evaluated will be included in this trial.

\section{Clinical Evaluation measures and follow up period}

Scientific assessments will be completed at reference and across 36 months following management in accordance with modified USPHS criteria via dual unconnected assessors (Table 2) $(31,34)$. The assessors completed a regimented exercising schedule before the trial starts. Marginal fit,
Marginal discoloration, Anatomic contour, Surface texture, Color match, were documented and gauged. In accordance with what was positive, the latter were, they were classified into Alpha, Bravo, or Charlie. Each issue was evaluated Alpha (A) in case of no problem, Bravo (B) in case of the lesser degree of the complication, Charlie (C) if the complication was major or if the restoration had to be removed to repair due to the complication, and Delta (D) or failure when the restoration had to be removed and cannot be repaired. If two assessors report conflicting estimations through the examination, a 3rd inspector will do an assessment, and the coinciding assessments from two inspectors will be employed for the study.

\section{Data collection}

The researchers utilized a case report form (CRF) (table 1) to gather records for the result investigation. The CRF incorporates demographic information, oral habits, medical history, and undesirable events. To safeguard the secrecy of cases, the patients recorded by the initial letters of their complete name on the model.

TABLE (3): Modified USPHS criteria

\begin{tabular}{|c|c|c|c|}
\hline \# & characteristic & rating & Criteria \\
\hline \multirow[t]{4}{*}{1} & \multirow[t]{4}{*}{ Marginal fit } & ALFA & Margin not noticeable, probe does not hook \\
\hline & & BRAVO & Probe hooks on margin but no space; dentin or liner exposed \\
\hline & & CHARLIE & Probe catches on border and gap on probing dentin or liner exposed \\
\hline & & DELTA & Fractured or missing Restoration \\
\hline \multirow[t]{3}{*}{2} & \multirow[t]{3}{*}{ Marginal discoloration } & ALFA & No discolored margin \\
\hline & & BRAVO & Discolored Margin, not entered towards pulp \\
\hline & & CHARLIE & Discolored Margin entered towards pulp \\
\hline \multirow[t]{4}{*}{3} & \multirow[t]{4}{*}{ Anatomic contour } & ALFA & Precise outline \\
\hline & & BRAVO & Slightly under- or overcontoured \\
\hline & & CHARLIE & Distinctly under- or overcontoured \\
\hline & & DELTA & broken or mobile Restorations \\
\hline \multirow[t]{3}{*}{4} & \multirow[t]{3}{*}{ Surface texture } & ALFA & Smooth, glazed, or glossy surface texture \\
\hline & & BRAVO & Slightly rough or dull surface \\
\hline & & CHARLIE & Surface with deep pores, cannot be refinished \\
\hline \multirow[t]{3}{*}{5} & \multirow[t]{3}{*}{ Color match } & ALFA & Clinically good (minor color deviation) \\
\hline & & BRAVO & Clinically satisfactory \\
\hline & & CHARLIE & Clinically unsatisfactory \\
\hline
\end{tabular}


Endocrowns were clinically inspected through a dental mirror and dental probe and the proximal contact visually checked with a string of waxed dental floss. Then confirmed by periapical $\mathrm{x}$-rays films. The occlusal contact inspected by special articulating papers in static and dynamic mandibular movements. Every variance in contour, restoration outline, and presence of secondary caries as contrasted to reference were notified and documented with digital photography.

A clinical researcher will inspect the obtained records and evaluate the record's credibility by matching the data with the therapeutic data. The records recorded twice into a database by specified workers and reviewed by a records supervisor

For this study, the first null hypothesis is no statistically significant differences between the evaluated criteria across the follow up periods, the second null hypothesis is no statistically significant differences between the evaluated criteria related to different restorative endocrown materials used with the age and gender correlated

\section{Statistical analysis}

The collected data were reviewed, organized, tabulated, and statistically analyzed using statistical package for social sciences (SPSS) version 26.0 for windows. The records will be investigated by a separate statistician. All statistical tests will be two-tailed. A P-value of less than 0.05 is the level of significance and a $95 \%$ confidence interval is calculated. Parametric methods are considered first. Data that do not conform to parametric assumptions or that cannot be transformed are analyzed using non-parametric methods.

Based on absolute and relative failures and success rates were calculated. Friedman one sample test will be used for intra-group comparisons, and Friedman two way-Anova two-sample tests will be used for inter-group comparisons. Qualitative variables will be analyzed by the Kruskal-Wallis test. The Bonferroni method will be used for multiple comparisons, and correlation tests to report the effect between all variables will be done.

TABLE (4) Eligibility and follow up periods

\begin{tabular}{|c|c|c|}
\hline \multicolumn{3}{|c|}{ Assessment for eligibility $n=40$} \\
\hline & Enrollment $\mathrm{n}=40 \mathrm{pt}$. & $\begin{array}{l}1 \text { pt. excluded, he refused to complete } \\
\text { the evaluation period }\end{array}$ \\
\hline \multicolumn{3}{|c|}{ Allocation baseline assessment } \\
\hline $\mathrm{N}=13$ by glass ceramic & $\mathrm{N}=13$ by zirconia polycrystalline & $\mathrm{N}=13$ by PEEK material \\
\hline \multicolumn{3}{|c|}{ Follow up $6 \mathrm{~m}$} \\
\hline $\mathrm{N}=13$ by glass ceramic & $\mathrm{N}=13$ by zirconia polycrystalline & $\mathrm{N}=13$ by PEEK material \\
\hline \multicolumn{3}{|c|}{ Follow up 1 year } \\
\hline $\mathrm{N}=13$ by glass ceramic & $\mathrm{N}=13$ by zirconia polycrystalline & $\mathrm{N}=13$ by PEEK material \\
\hline \multicolumn{3}{|c|}{ Follow up $18 \mathrm{~m}$} \\
\hline $\mathrm{N}=13$ by glass ceramic & $\mathrm{N}=121$ restoration deboned & $\mathrm{N}=13$ \\
\hline \multicolumn{3}{|c|}{ Follow up 2 year } \\
\hline $\begin{array}{l}\mathrm{N}=12 \text { 1patient lost to follow up due to } \\
\text { fracture of restoration }\end{array}$ & $\mathrm{N}=12$ & $\mathrm{~N}=13$ \\
\hline \multicolumn{3}{|c|}{ Follow up to $30 \mathrm{~m}$} \\
\hline $\mathrm{N}=12$ & $\mathrm{~N}=12$ & $\mathrm{~N}=13$ \\
\hline \multicolumn{3}{|c|}{ Follow up of 3 years } \\
\hline $\mathrm{N}=12$ & $\mathrm{~N}=12$ & $\mathrm{~N}=13$ \\
\hline
\end{tabular}




\section{RESULTS}

The number of cases finally evaluated 39 cases divided into three groups according to the type of endocrown construction materials and along the following period two male cases rejected after failure and the statistics analyzed on the 36 cases with three groups of endocrown materials (lithium disilicate 12 case, zirconia 12 case and PEEK group 13 case). These cases distributed among 25 male and 12 female with age range about 39.34 years and there is no effect of age or gender type in the clinical performance except patient satisfaction which forward to Charlie rating for female more than male especially at the 36 month follow up period.

Conclusive failures were defined as clinically intolerable breakage, that need obligatory substitution of the restoration, inacceptable (= Delta rating or unrepaired Charlie rating) untreated secondary caries, restoration fracture or debonding. Relative failures were defined as minimal cohesive fractures and minor cracks, which were clinically acceptable, as well as minor marginal stains and minor deviations in marginal fit or any defect in restoration can be repaired intraorally.

The inter groups statistically analyzed by related-samples Friedman's two-way analysis of variance by ranks, the null hypothesis was rejected to all groups because statistically significant differences are presented between the sequenced evaluation periods. so Pairwise correlation and Significance values have been adjusted by the Bonferroni correction for multiple tests. Each row tests the null hypothesis that the Sample 1 and Sample 2 distributions are the same. Asymptotic significances (2-sided tests) are displayed. The significance level is .05 . all follow up periods of baseline (0), $6 \mathrm{~m}, 12 \mathrm{~m}$ and 18 month have statistically significant differences with the periods $30 \mathrm{~m}$ and $36 \mathrm{~m}$ respectively due the graduation transformation from ALPHA rating to BRAVO and finally CHARLIE rating.

Due to three distinct groups of independent variables, the Independent-Samples Kruskal-Wallis Test was applied and when the evaluation results that re- ject the null hypothesis, the pairwise comparison applied as following.

The null hypothesis related to The marginal fit was rejected and the pairwise comparison reported statistically significant differences between the lithium disilicate and zirconia group and between zirconia group with PEEK group, but the lithium disilicate and PEEK groups had no statistically significant differences this means that lithium disilicate group is the best followed by PEEK group then zirconia group as showed in table(5) and figure(1).

2-The null hypothesis related to The marginal discoloration was rejected and the pairwise comparison reported statistically significant differences between the lithium disilicate and (zirconia group and PEEK group) and no statistically significant differences between zirconia group with PEEK group, this means that lithium disilicate group is the best followed by zirconia group then PEEK group as showed in table(5) and figure(1).

The color match criteria statistics showed no statistically significant differences between lithium disilicate and PEEK groups but statistically significant differences between lithium disilicate and zirconia and between zirconia and PEEK groups, this means the best group is zirconia, lithium disilicate and PEEK groups respectively. table (5) fig. (1)

The null hypothesis related to The surface texture was rejected and the pairwise comparison reported statistically significant differences between the lithium disilicate and (zirconia group and PEEK group) and no statistically significant differences between zirconia group with PEEK group, this means that lithium disilicate group is the best followed by zirconia group then PEEK group as showed in table (5) and figure (1).

Related to anatomic contour group no statistically significant differences were presented so not pairwise comparison applied. Table (5)

The two-way ANOVA reported no statistically significant differences between all criteria evaluated and the interaction variable of age and gender. 
TABLE (5): Pairwise Comparisons of the type of endocrown materials related to tested criteria

\begin{tabular}{|c|c|c|c|c|c|c|}
\hline $\begin{array}{l}\text { Tested } \\
\text { criteria }\end{array}$ & Sample 1-sample 2 & Test statistic & Std. Error & $\begin{array}{l}\text { Std. test } \\
\text { statistic }\end{array}$ & Sig. & Adj. sig. \\
\hline \multirow{3}{*}{ 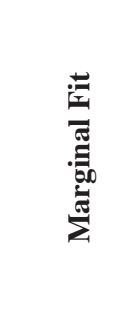 } & $\begin{array}{l}\text { zirconia endocrown-lithium } \\
\text { disilicate endocrown }\end{array}$ & 4.625 & 2.090 & 2.213 & .027 & .081 \\
\hline & $\begin{array}{l}\text { zirconia endocrown-peek } \\
\text { endocrown }\end{array}$ & -4.625 & 2.049 & -2.257 & .024 & .072 \\
\hline & $\begin{array}{l}\text { lithium disilicate } \\
\text { endocrown-peek endocrown }\end{array}$ & .000 & 2.049 & .000 & 1.000 & 1.000 \\
\hline \multirow{3}{*}{ 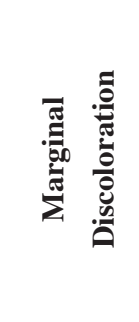 } & $\begin{array}{l}\text { zirconia endocrown-lithium } \\
\text { disilicate endocrown }\end{array}$ & -6.875 & 4.005 & -1.717 & .086 & .258 \\
\hline & $\begin{array}{l}\text { zirconia endocrown-peek } \\
\text { endocrown }\end{array}$ & -10.375 & 3.927 & -2.642 & .008 & .025 \\
\hline & $\begin{array}{l}\text { lithium disilicate } \\
\text { endocrown-peek endocrown }\end{array}$ & -3.500 & 3.927 & -.891 & .373 & 1.000 \\
\hline \multirow{3}{*}{ 弟 } & $\begin{array}{l}\text { zirconia endocrown-lithium } \\
\text { disilicate endocrown }\end{array}$ & -6.875 & 4.005 & -1.717 & .086 & .258 \\
\hline & $\begin{array}{l}\text { zirconia endocrown-peek } \\
\text { endocrown }\end{array}$ & -10.375 & 3.927 & -2.642 & .008 & .025 \\
\hline & $\begin{array}{l}\text { lithium disilicate } \\
\text { endocrown-peek endocrown }\end{array}$ & -3.500 & 3.927 & -.891 & .373 & 1.000 \\
\hline \multirow{3}{*}{ 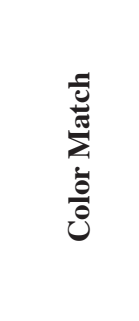 } & $\begin{array}{l}\text { zirconia endocrown-lithium } \\
\text { disilicate endocrown }\end{array}$ & 4.625 & 2.090 & 2.213 & .027 & .081 \\
\hline & $\begin{array}{l}\text { zirconia endocrown-peek } \\
\text { endocrown }\end{array}$ & -4.625 & 2.049 & -2.257 & .024 & .072 \\
\hline & $\begin{array}{l}\text { lithium disilicate } \\
\text { endocrown-peek endocrown }\end{array}$ & .000 & 2.049 & .000 & 1.000 & 1.000 \\
\hline $\begin{array}{l}\text { Anatomic } \\
\text { Contour }\end{array}$ & \multicolumn{6}{|l|}{ Retain the null hypothesis } \\
\hline $\begin{array}{l}\text { Asymptoti } \\
\text { a. Significa }\end{array}$ & hificances (2-sided tests) are & layed. The s & cance leve & & & \\
\hline
\end{tabular}




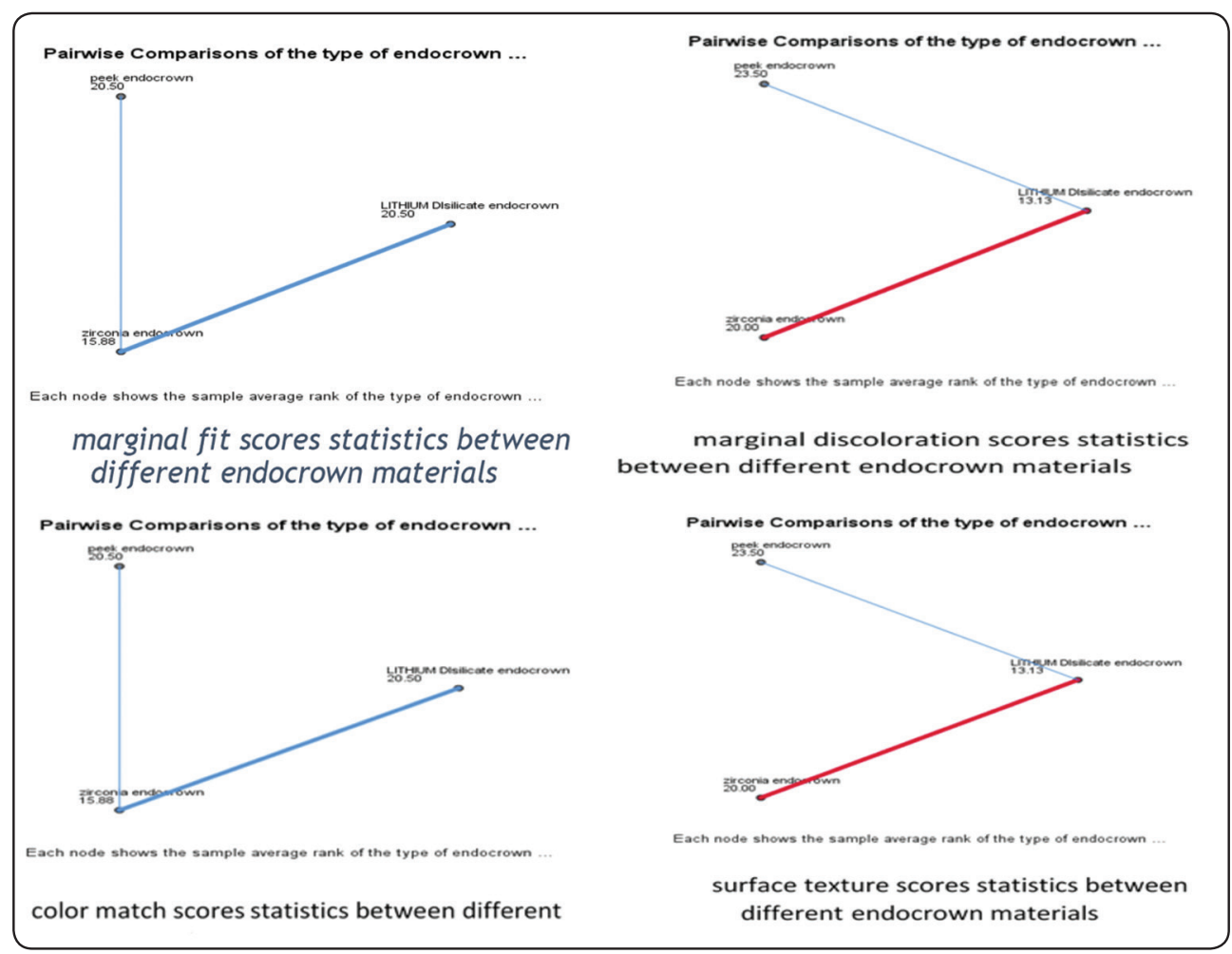

Fig. (2) bar chart represent Pairwise Comparisons of the type of endocrown materials related to tested significant criteria

\section{DISCUSSION}

In this cohort study of translucent zirconia, lithium disilicate, and modified PEEK endocrown restoring single endodontically lower first posterior teeth, one endocrown fracture, one endocrown deretained, and no teeth damage were found, resulting in a high survival rate $(94.87 \%$ ). Moreover, the practical results estimated by the USPHS criteria (Marginal fit, Marginal discoloration, Anatomic contour, Surface texture, Color match) were extremely satisfactory too. Consistent with the USPHS criteria, the clinical quality of all endocrowns was in a suitable and preferred range as the first and second null hypotheses were rejected but all cases did not report the failure condition along the examination periods except two case rejected from follow up period. In some cases, the necessary corrections were accomplished and there was no essential for substitution of the endocrown.
The results of this clinical study agree that CAD-CAM endocrowns are an effective treatment solution for the restoration of extensively damaged endodontically treated molars. Excellent survival rates have been reported $(94.87 \%)$. Clinical performance is also satisfactory and comparable with that observed for molars restored by using crowns. Also, endocrowns had fewer catastrophic failures $0 \%$ of root fractures. two cases considered failures found in two endocrowns were due to loosening (one case from zirconia cases) and fracture in one case of lithium disilicate cases and excluded from evaluation by total (37 case).

The sum of patients studied in the present study is concurrent with the present literature. ${ }^{31}$

Special preparations are recommended for the creation of endocrown. A modification on the outline of the endocrown is probable to augment the aesthetics and biomechanical characteristics of the definitive restoration. Along with other factors, the 
reinforcement material affects the design of the preparation concerning the complete reduction in the height of the occlusal surface. Authors ${ }^{(30)}$ advised When endocrown ceramic materials are used as in the present study, it is recommended to reduce the axial direction by at least $2 \mathrm{~mm}$.

Regarding the choice of materials used and related to survival rate due to debonding or irreparable fracture, the modified PEEK materials have some interesting characteristics for endocrown fabrication, thanks to their modulus of elasticity, which is similar to that of dentin and thus limits irreparable fractures, while retaining a high fracture resistance. However, a decrease in elastic modulus reduces stress in the dentin while increasing it at the interface, thus leading to risks of debonding and detachment of the prosthesis and preservation the tooth integrity, this correlated with the finding of our study where the rate of Bravo and Charlie recorded to all cases at the 36 month examination period. ${ }^{(32)}$

Because the marginal fit and marginal discoloration interrelated and integrated criteria, in this study, the good marginal fit especially the monolithic zirconia crowns recorded excellent grade. During the second year the record of Bravo rate increased from lithium disilicate, translucent zirconia and modified PEEK endocrown respectively, this in conformity with laboratory researches have revealed that the marginal adaptation of the monolithic restorations can be disturbed by numerous issues. Especially, Hamza et al. revealed that different CAD/ CAM systems show changed marginal discrepancy of the monolithic crowns and Kale et al. showed that the marginal fit of the monolithic crowns can be influenced by the bonding mechanisms, however it was inside the tolerable scale $\left(<120 \_\mathrm{m}\right){ }^{[33,34]}$.

The clinical examination of the current study recorded Charlie rate for marginal fit and discoloration ( 6 cases) at the 36 month examination time for translucent zirconia but the lithium disilicate and modified PEEK endocrown recorded
Bravo rate at the same examination period may be due to difficulties in surface treatment and bonding procedure to translucent zirconia ,this in disagreement study evaluated the adaptation of crown margin between metal-ceramic, lithium disilicate, and monolithic single crowns and they reported that the monolithic restoration have considerably better marginal adaptation in contrast to Lithium Disilicate restoration ${ }^{[35]}$.

The assessment of the modified USPHS criteria exposed an important alteration in surface roughness, marginal adaptation, and marginal discoloration across 36 months follow up. So, the total assessed success rate of endocrown restorations was after 36 months (92.3\%) for lithium disilicate group, one cases deboned and treated by rebonding but calculated as failure for translucent zirconia but for modified PEEK endocrown the rate of marginal discoloration recorded Charlie in six case at the 36 month examination and this correlated also Charlie rating in all cases for surface texture or roughness for the same examination period and this may due to marginal deterioration, cement aging and less marginal fitting than ceramic material .this in agreement with studies reported that the degradation progressions of the bonding interface were typically ascribed to the decrease of the degree of crown margin integration ${ }^{[36]}$. Marginal worsening, particularly for Inlay prosthesis, has also been focused by other in vivo and in vitro researches ${ }^{[37,38,39]}$. But the liability of the bonding agent for aging did not influence the experimental performing and did not result in substitution of any crowns or prosthesis.

In addition, the fracture resistance observed for the varied materials considered was mainly greater than the masticatory forces. As the risk of debonding has been shown to be greater than the risk of fracture, materials with the greatest adhesion values, such as lithium disilicate, are the best choice. Based on ,the finding of this study synchronized with this interpretation, whereas the success of lithium disilicate endocrowns was $100 \%$ along the 
36 months examination period related to bonding but one case fractured may be due high masticatory force or uniaxial force especially the high force at the first molar area, but modified peek endocrowns was $100 \%$ between alpha and Bravo rating 30 months but after that number of cases rated Charlie more than the other cases, however the satisfaction of patients rated charlie in 4 cases and these cases repaired to the successor criteria. Collectively the lithium disilicate the best because they have the highest score of alpha rate and Bravo rate more than zirconia and PEEK cases ${ }^{40}$.

One of the findings of this study, no significant changes between the tested materials statistically related to anatomic contour, but the endocrowns fabricated with the CAD/CAM technique of lithium disilicate and translucent zirconia demonstrates superior anatomic contour and stabilized interproximal contact along the full examination period as rated alpha and Bravo but the cases of modified PEEEK materials have good anatomic contour and interproximal contact as rated alpha and Bravo to the 30 months period but at 36 month examination period the cases recorded Charlie rating,this may due to inherent weakness of resinous materials and residual polymerization shrinkage lead to degradation the material but can be repaired to good contour by addition of resin composite. Another probable clarification to this could be that more than the 1-1.2 mm thickness of the resin nanoceramic CAD/ CAM material used was not able to tolerate occlusal and lateral forces (masticatory forces) in the region of the occlusal and interproximal contact. ${ }^{[41]}$.

Another clinical observation was the esthetic properties of the lithium disilicate and translucent zirconia are unequaled by modified PEEK materials, which can be an advantage for some patients. Ceramics also age better and have a lower plaque retention than modified PEEK material, so slight color difference between the endocrown restoration and tooth especially with the extended examination period, all cases of lithium disilicate and translucent zirconia rated alpha or Bravo along the complete examination period but the modified PEEK also except the at 36 months period rated charlie and this score also recorded for the surface texture criteria and this may be due to roughening the surface and other factors as inherent discoloration of resinous, improper oral hygiene, smoking especially male cases and drinks. ${ }^{40}$

In our study, the surface texture of the restorations rated with alpha and Bravo for the all the tested materials during the 36 months follow up periods but the rate of Bravo steadily increased with time with exception at 36 months the modified PEEK endocrown recorded charlie rate. There are numerous reasons that can influence the surface texture like tooth cleaning, abrasion, or attrition ${ }^{[42,43]}$.

Regarding the clinical outcomes rated by USPHS criteria, no significant differences were found between the follow-up examinations of translucent zirconia and lithium disilicate, but the modified PEEK recorded Charlie rating at 36-month period only. Of the translucent zirconia restorations, $100 \%$ were rated with Bravo for color match at only the 36-month examination period. The lost transparency and the bright opacity inhibit the effective shade match related to translucent zirconia. The small discrepancy of color was already noticed at the phase of final endocrown bonding. Despite this shade discrepancy, the participants were gratified with the shade and accepted for the final delivery. Comparable results were also described from Worni et al., and this outcome emphasizes the problem to accomplish the preferred result only by veneering shades ${ }^{[44,45]}$.

The recent resin nanoceramic restorative materials offer benefits such elastics modulus similar to dentin, less flaw spreads, greater fracture resistance as against ceramics that are more liable to crack owing to brittle nature ${ }^{[46-49]}$. However, it offer disadvantages such as higher microleakage by time ${ }^{[50]}$ and are weaker than lithium disilicate ceramics under lateral loadings ${ }^{[51]}$. Furthermore, the high survival rates of translucent zirconia endocrown 
displayed in this trial are also strengthened by the results of other studies ${ }^{[35,52,53]}$.

Finally, the best clinical outcome was observed in the clinical case were fabricated from lithium disilicate ceramic in all the tested criteria After three years, every clinical characteristic was rated as Alfa or Bravo. Followed by or equal to translucent zirconia then the resinous material (PEEK), these results comparable to several clinical findings that lithium disilicate may be the most desirable materials for the construction of an endocrown because of the formation of a greater bonding between resin cement and tooth tissues ${ }^{[35,2]}$.

All in all, the clinical success of endocrowns of our study for lithium disilicate, translucent zirconia and modified PEEK $\mathbf{9 4 . 8 7 \%}$ this correlated with the few clinical studies accessible currently exhibit clinical survival percentage of endocrown that varies from $94 \%-100 \%$ in a 3 -years period [54], while their 10-year survival rate was set to $98.8 \%{ }^{[55]}$. Otto et al. ${ }^{[56]}$ in 2015 reported that the sucess rate of Cerec constructed feldspathic endocrowns in Molars and Premolars was set to $90.5 \%$ and $75 \%$ respectively, in a 12-year follow up period.

The lack of standardization among different studies may limit the comparison between results because the adaptation depends on several factors. These include the type of restoration (crowns, inlays, onlays, and endocrowns), the different materials tested, the method of fabrication, the precision of the scanning and milling systems, the cement space, the size of the milling rotary instrument, and the measurement techniques used. The current trail has some limits (like the number of participants involved, the restricted number of endocrowns studied, the short follow-up period, and the workflow was not totally digital).

\section{CONCLUSIONS}

Within the limitations of this prospective clinical study, CAD/CAM-fabricated endocrowns displayed promising outcomes after a study episode of 3 years, guiding to the deductions that.

1. The three types of restoration were a promising substitute and a more minimal invasive restorative regime for Endodontically treated teeth.

2. Lithium disilicate glass may be the best desirable materials for the construction of an endocrown due to the formation of a greater bond between resin cement and tooth tissues

3. The translucent zirconia restorations constructed with CAD/CAM technology is a practical option for the endocrown restoration of single posterior teeth. This study revealed no fracture of single-tooth translucent endocrowns and the success rate was high.

4. PEEK might be believed another structure material for endocrown restorations. The additional long-term clinical proof is needed to determine the use of this material as an alternative for the usual ceramic.

\section{Conflict of interest}

The authors affirm that they have no conflict of interest.

\section{Ethical approval}

All procedures accomplished in this study agreed with the ethical standards of the ethics committee of the hospitals of Assiut University with registered number 3-263542 and with the 1964 Helsinki Declaration and its later amendments.

\section{Informed consent}

Informed consent was obtained from all the participants included in the study.

\section{The study not funded by anyone}

Special acknowledgment to all assistant lectures. Interns and evaluators in the fixed prosthodontics department, faculty of dentistry, Assiut university for help, support, and cooperation. 


\section{Conflict of interest}

The authors declare that they have no conflict of interest.

\section{Ethical approval}

All procedures performed in this study were in accordance with the ethical standards of the ethics committee of the hospitals of Assiut University and with the 1964 Helsinki Declaration and its later amendments.

\section{Informed consent}

Informed consent was obtained from all of the participants included in the study.

\section{The study not funded from any one}

Special acknowledgement to all assistant lectures. interns and evaluators in the fixed prosthodontics department, faculty of dentistry, Assiut university for help, support and cooperation.

\section{REFERENCES}

1. J.A. Sedrez-Porto et al. Endocrown restorations: A systematic review and meta-analysis. Journal of Dentistry 52 (2016) 8-14

2. Nicolas Govare, and Mathieu Contrepois. Endocrowns: A systematic review. (J Prosthet Dent 2019; -: ---) article in press.

3. Bindl A, Mormann WH. Clinical evaluation of adhesively placed cerec endocrowns after 2 years-preliminary results. J Adhes Dent 1999; 1:255-65.

4. Pissis P. Fabrication of a metal-free ceramic restoration utilizing the monobloc technique. Pract Periodontics Aesthet Dent 1995; 7:83-94.

5. Sedrez-Porto JA, Rosa WL, da Silva AF, Munchow EA, Pereira-Cenci T. Endocrown restorations: A systematic review and meta-analysis. J Dent 2016; 52:8-14.

6. Helal MA, Wang Z. Biomechanical assessment of restored mandibular molar by endocrown in comparison to a glass fiber post-retained conventional crown: 3D finite element analysis. J Prosthodont 25 Oct 2017.
7. Bindl A, Mörmann WH. Clinical evaluation of adhesively placed Cerec endocrowns after 2 years-preliminary results. J Adhes Dent 1999; 1:255-65.

8. Gracis S, Thompson VP, Ferencz JL, Silva NR, Bonfante EA. A new classification system for all-ceramic and ceramic-like restorative materials. Int J Prosthodont. 2015; 28:227-35

9. El-Damanhoury HM, Haj-Ali RN, Platt JA. Fracture resistance and microleakage of endocrowns utilizing three CAD-CAM blocks. Oper Dent.2015;40:201-10.

10. Otto T. Computer-aided direct all-ceramic crowns: preliminary 1-year results of a prospective clinical study. Int J Periodontics Restorative Dent 2004;24: 446-55.

11. Göhring T, Peters A. Restoration of endodontically treated teeth without posts. Am J Dent 2003; 16:313-8.

12. Tysowsky G. The science behind lithium disilicate: a metal-free alternative. Dent Today 2009; 28:112-3.

13. Qin F, Zheng S, Luo Z, Li Y, Guo L, Zhao Y, Fu Q. Evaluation of machinability and flexural strength of a novel dental machinable glass-ceramic. J Dent 2009; 37:776-80

14. Mrazek WR. Laboratory procedures for fabricating pressable all-ceramic restorations. J Dent Technol 1997; $14: 21-31$.

15. Kwon SJ, Lawson NC, McLaren EE, et al: Comparison of the mechanical properties of translucent zirconia and lithium disilicate. J Prosthet Dent 2018; 120:132-137

16. Zhang Y, Lawn BR: Novel zirconia materials in dentistry. J Dent Res 2018; 97:140-147.

17. Makhija SK, Lawson NC, Gilbert GH, Litaker MS, McClelland JA, Louis DR, et al. Dentist material selection for single-unit crowns: Findings from the National Dental Practice-Based Research Network. J Dent 2016; 55:40-7.

18. Katzer A, Marquardt H, Westendorf J, Wening JV, von Foerster G. Polyetheretherketoned cytotoxicity and mutagenicity in vitro. Biomaterials 2002; 23:1749-59.

19. Adler S, Kistler S, Kistler F, Lermer J, Neugerbauer J. Compression-moulding rather than milling: a wealth of possible applications for high performance polymers. Quintessenz Zahntech 2013; 39:376-84.

20. Neugebauer J, Adler S, Kisttler F, Kistler S, Bayer G. The use of plastics in fixed prosthetic implant restoration. ZWR 2013; 122:242-5. 
21. Rzanny A, Gobel F, Fachet M. BioHPP summary of results for material tests. Research Report. Department of Materials and Technology, University of Jena, Jena, Germany, 2013. Available at: http://www.bredent.co.uk/ downloads/technical/BioHPP_clinical_research_data.pdf. Accessed September 16, 2016.

22. Stawarczyk B, Jordan P, Schmidlin PR, Roos M, Eichberger M, Gernet W, et al. PEEK surface treatment effects on tensile bond strength to veneering resins. J Prosthet Dent 2014; 112:1278-88.

23. Fuhrmann G, Steiner M, Freitag-Wolf S, Kern M. Resin bonding to three types of polyaryletherketones (PAEKs)durability and influence of surface conditioning. Dent Mater 2014; 30:357-63.

24. Kern M, Lehmann F. Influence of surface conditioning on bonding to polyetheretherketone (PEEK). Dent Mater 2012; 28:1280-3.

25. Schmidlin PR, Stawarczyk B, Wieland M, Attin T, Hammerle CHF, Fischer J. Effect of different surface pretreatments and luting materials on shear bond strength to PEEK. Dent Mater 2010; 26:553-9.

26. Koutouzis T, Richardson J, Lundgren T. Comparative soft and hard tissue responses to titanium and polymer healing abutments. J Oral Implantol 2011;37(Spec No):174-82.

27. Santing HJ, Meijer HJ, Raghoebar GM, Ozcan M. Fracture strength and failure mode of maxillary implant-supported provisional single crowns: a comparison of composite resin crowns fabricated directly over PEEK abutments and solid titanium abutments. Clin Implant Dent Relat Res 2012; 14:882-9.

28. Tetelman ED, Babbush CA. A new transitional abutment for immediate aesthetics and function. Implant Dent 2008; $17: 51-8$

29. Costa-Palau S, Torrents-Nicolas J, Brufau-de Barbera M, Carbatosa-Termes J. Use of polyetheretherketone in the fabrication of a maxillary obturator prosthesis: a clinical report. J Prosthet Dent 2014; 112:680-2.

30. Michel Fages; Bertrand Bennasar. The endocrown: a different type of all-ceramic reconstruction for molars. J Can Dent Assoc 2013;79: d140

31. F.A. Spitznagel1 \& K.J. Scholz2 \& J.R. Strub3 \& K. Vach4 \& P.C. Gierthmuehlen1. Polymer-infiltrated ceramic $\mathrm{CAD} / \mathrm{CAM}$ inlays and partial coverage restorations: 3 -year results of a prospective clinical study over 5 years. Clinical Oral Investigations (2018) 22:1973-1983
32. Zhu J, Rong Q, Wang X, Gao X. Influence of remaining tooth structure and restorative material type on stress distribution in endodontically treated maxillary premolars: A finite element analysis. J Prosthet Dent 2017;117: 646-55.

33. Hamza, T.A.; Sherif, R.M. In vitro evaluation of marginal discrepancy of monolithic zirconia restorations fabricated with different CAD-CAM systems. J. Prosthet. Dent. 2017, 117, 762-766. [CrossRef] [PubMed]

34. Kale, E.; Yilmaz, B.; Seker, E.; Özcelik, T.B. Effect of fabrication stages and cementation on the marginal fit of CAD-CAM monolithic zirconia crowns. J. Prosthet. Dent. 2017, 118, 736-741. [CrossRef] [PubMed]

35. Sarıkaya, I.; Hayran, Y. Effects of dynamic aging on the wear and fracture strength of monolithic zirconia restorations. BMC Oral Health 2018, 18, 146.

36. Guess PC, Selz CF, Voulgarakis A, Stampf S, Stappert CF (2014) Prospective clinical study of press-ceramic overlap and full veneer restorations: 7-year results. Int J Prosthodont 27(4):355-358.

37. FederlinM, Hiller KA, Schmalz G (2014) Effect of selective enamel etching on clinical performance of $\mathrm{CAD} /$ CAM partial ceramic crowns luted with a self-adhesive resin cement. Clin Oral Investig 18(8):1975-1984

38. Frankenberger R, Lohbauer U, Schaible RB, Nikolaenko SA, Naumann M (2008) Luting of ceramic inlays in vitro: marginal quality of self-etch and etch-and-rinse adhesives versus self-etch cements. Dent Mater 24(2):185-191

39. Frankenberger R, Taschner M, Garcia-Godoy F, Petschelt A, Krämer N (2008) Leucite-reinforced glass ceramic inlays and onlays after 12 years. J Adhes Dent 10(5):393-398

40. Kamonwanon P, Hirose N, Yamaguchi S, Sasaki J-I, Kitagawa H, Kitagawa R, et al. SiO2-nanocomposite film coating of CAD/CAM composite resin blocks improves surface hardness and reduces susceptibility to bacterial adhesion. Dent Mater J 2017; 36:88-94.

41. Kollmuss M, Jakob FM, Kirchner HG, Ilie N, Hickel R, Huth KC (2013) Comparison of biogenerically reconstructed and waxed-up complete occlusal surfaces with respect to the original tooth morphology. Clin Oral Investig 17(3):851-857

42. Amer, R.; Kürklü, D.; Johnston, W. Effect of simulated mastication on the surface roughness of three ceramic systems. J. Prosthet. Dent. 2015, 114, 260-265. [CrossRef] [PubMed] 
43. Lawson, N.C.; Bansal, R.; Burgess, J.O. Wear, strength, modulus and hardness of $\mathrm{CAD} / \mathrm{CAM}$ restorative materials. Dent. Mater. 2016, 32, e275-e283.

44. Worni, A.; Katsoulis, J.; Kolgeci, L.; Worni, M.; MericskeStern, R. Monolithic zirconia reconstructions supported by teeth and implants: 1- to 3-year results of a case series. Quintessence Int. 2017, 48, 459-467. [PubMed]

45. Bömicke, W.; Rammelsberg, P.; Stober, T.; Schmitter, M. Short-Term Prospective. Clinical Evaluation of Monolithic and Partially Veneered Zirconia Single Crowns. J. Esthet. Restor. Dent. 2017, 29, 22-30. [CrossRef][PubMed]

46. Zhu J, Rong Q, Wang X, Gao X. Influence of remaining tooth structure and restorative material type on stress distribution in endodontically treated maxillary premolars: a finite element analysis. J Prosthet Dent 2017; 117: 646-655.

47. Chen C, Trindade FZ, de Jager N, Kleverlaan CJ, Feilzer AJ. The fracture resistance of a CAD/CAM Resin Nano Ceramic (RNC) and a CAD ceramic at different thicknesses. Dent Mater 2014; 30:954-962.

48. Gaintantzopoulou MD, El-Damanhoury HM. Effect of preparation depth on the marginal and internal adaptation of computer-aided design/computer-assisted manufacture endocrowns. Oper Dent 2016; 41:607-616.

49. Awada A, Nathanson D. Mechanical properties of resinceramic CAD/CAM restorative materials. J Prosthet Dent 2015; 114:587-593.
50. El-Damanhoury HM, Haj-Ali RN, Platt JA. Fracture resistance and microleakage of endocrowns utilizing three CAD-CAM blocks. Oper Dent 2015; 40:201-210.

51. Gresnigt MM, Özcan M, van den Houten ML, Schipper L, Cune MS. Fracture strength, failure type and Weibull characteristics of lithium disilicate and multiphase resin composite endocrowns under axial and lateral forces. Dent Mater 2016; 32:607-614.

52. Worni,A.; Katsoulis, J.; Kolgeci, L.; Worni, M.; MericskeStern, R. Monolithic zirconia reconstructions supported by teeth and implants: 1- to 3-year results of a case series. Quintessence Int. 2017, 48, 459-467. [PubMed]

53. Bömicke, W.; Rammelsberg, P.; Stober, T.; Schmitter, M. Short-Term Prospective. Clinical Evaluation of Monolithic and Partially Veneered Zirconia Single Crowns. J. Esthet. Restor. Dent. 2017, 29, 22-30.

54. Belleflamme MM, Geerts SO, Louwette MM, Grenade CF, Vanheusden AJ, Mainjot AK. No post-no core approach to restore severely damaged posterior teeth: an up to 10 year retrospective study of documented endocrown cases. J Dent 2017; 63:1-7.

55. Sedrez-Porto JA, Rosa WL, da Silva AF, Münchow EA, Pereira-Cenci T. Endocrown restorations: a systematic review and meta-analysis. J Dent 2016; 52:8-14.

56. Otto T, Mörmann WH. Clinical performance of chairside $\mathrm{CAD} / \mathrm{CAM}$ feldspathic ceramic posterior shoulder crowns and endocrowns up to 12 years. Int J Comput Dent 2015; 18:147-161. 